\title{
Nutrition and Healthy Diets for All: A Key to Meeting the Sustainable Development Goals
}

\section{Meenakshi Bakshi Mehan*}

Professor and Head, Department of Foods and Nutrition, Faculty of Family and Community Sciences, The Maharaja Sayajirao University of Baroda, Vadodara and Member in National Technical Board on Nutrition, NITI AYOG, New Delhi, India

*Corresponding Author: Meenakshi Bakshi Mehan, Professor and Head, Department of Foods and Nutrition, Faculty of Family and Community Sciences, The Maharaja Sayajirao University of Baroda, Vadodara and Member in National Technical Board on Nutrition, NITI AYOG, New Delhi, India.

DOI: 10.31080/ASNH.2020.04.0632

The world today faces a grave nutrition situation, Malnutrition (under nutrition and overweight/obesity) is affecting almost all the countries of the globe, having adverse consequences on development with very high human consequences. The present era offers us the greatest opportunity to end malnutrition, like never before.

The UN Decade of Action on Nutrition 2016-2025 and the Sustainable Development Goals (SDGs) provide global and national guidance to combat malnutrition and accelerate progress. The burden of malnutrition across the world remains unacceptably high, and progress unacceptably slow. Both maternal and child malnutrition followed by dietary risk factors are responsible for more burden of disease than any other cause. Globally, six out of top 9 risk factors driving the global burden of disease are nutrition and diet related. Poor diets are now considered a greater risk factor for morbidity and mortality than air pollution, tobacco, alcohol and drug abuse combined (Global Burden of Disease 2016). In India also, seven out of the top 17 DALY's (Disability adjusted life years: a indicator of economic development of the country) attributable to risk factors are related to nutrition and diet. They are in order of importance: child and maternal malnutrition, dietary risks, high systolic blood pressure, high fasting plasma blood glucose, high total cholesterol levels, high body mass index, impaired kidney function and low bone mineral density (DALY"S attributable to risk factors in India, 2016).

Thus, it is being increasingly recognized now that nutrition actions need to be focused, if the world wants to achieve sustainable development goals by 2030. Twelve out of total seventeen sustainable development goals are related to nutrition. SDG 1 (End poverty in all its forms everywhere) to reduce poverty requires improved access to adequate diet for poor and hungry, goal 2 (End hunger, achieve food security and improved nutrition and promote sustainable agriculture) strives to give impetus to agriculture and food security for improving nutrition, Goal 3 (ensuring healthy lives and promote well being for all at all ages) currently $45 \%$ of deaths in children below five years are related to under nutrition, on the other hand around $71 \%$ of deaths in adults are due to diet related non communicable diseases and so on. Similarly diet quality is also related to 11 sustainable development goals. Thus to advance progress on SDG's we must prioritize diet quality and nutrition in national plans and strategies with clear implementation plans and committed leadership.

India is also fortunate to have an enabling environment for $\mathrm{Nu}$ trition with the launch of National Nutrition Mission on 8 March 2018 with an ambitious target of reducing the prevalence of stunting from $38.4 \%$ to $25 \%$ by 2022 . India also had its own National Nutrition Strategy "Nourishing India", released in 2017, and lists the high priority districts in the country with a goal of Malnutrition-free India. The National Nutrition Mission envisages inter sectoral collaborations with ministry of women and child development, ministry of health and family welfare, ministry of drinking water and sanitation and with other key stakeholders. Similarly, The National Health Policy, 2017 recommended strengthening the delivery of Primary Health Care, through establishment of "Health and Wellness Centres" as the platform to deliver Comprehensive Primary Health Care and called for a commitment of two thirds of the health budget to primary health care. In February 2018, the Government of India announced that 1,50,000 Health and Wellness Centres (HWCs) would be created by transforming existing Sub Health Centres and Primary Health Centres to deliver Comprehen- 
sive Primary Health Care and declared this as one of the two components of Ayushman Bharat. This was the first step in the conversion of policy articulations to a budgetary commitment.

However, in the era of sustainable development goals we have to also look at sustainable actions to improve nutrition and diets and it is recommended that government of India also invests in making healthy diets available, accessible, affordable and acceptable to all the populations especially the poor and vulnerable populations. For this India needs to focus on efforts to form sustainable and resilient food systems for healthy diets, our trade and investments should have nutrition focus, we should create safe, healthy and supportive environments to deliver essential nutrition actions in all age groups and strengthen governance and accountability for nutrition.

In order to work towards the above mentioned goals, It is time that foods and nutrition has its own ministry to plan and implement national nutrition policy (India's national nutrition policy was framed in 1993 with no further updates) with the whole population approach as malnutrition is seen in all the income groups of our country. Nutrition being multi sect oral in nature, In order to improve nutrition outcomes of our country convergence between various ministries will be required, therefore the Ministry of Foods and Nutrition should be directly under the control of prime minister's office so that identification of nutrition targets and indicators for monitoring within each ministry could be identified and reviewed regularly by PMO with a common goal of improving diets and nutrition of entire India's population which will give great impetus to our nations development.

\section{Assets from publication with us}

- Prompt Acknowledgement after receiving the article

- Thorough Double blinded peer review

- Rapid Publication

- Issue of Publication Certificate

- High visibility of your Published work

Website: https://www.actascientific.com/

Submit Article: https://www.actascientific.com/submission.php

Email us: editor@actascientific.com

Contact us: +919182824667 